\title{
The first record of Valgothrombium (Acari: Microtrombidiidae) from Iran with description of a new species
}

\author{
Nasir SABERI-RISEH 1 (D), Alireza SABOORI ${ }^{1,3}$ (D), Mahdieh ASADI 2 (D), Azadeh ZAHEDI GOLPAYEGANI ${ }^{\mathbb{D}}$, Jamasb \\ NOZARI ${ }^{1}$ (D)
}

${ }^{1}$ Department of Plant Protection, Faculty of Agriculture, University of Tehran, Karaj, Iran

${ }^{2}$ Department of Plant Protection, College of Agriculture, Shahid Bahonar University of Kerman, Kerman, Iran

${ }^{3}$ Corresponding author: saboori@ut.ac.ir

Received: 11 July 2020

Accepted: 27 July 2020

Available online: 29 July 2020

\begin{abstract}
A new species Valgothrombium takhtii Saberi-Riseh \& Saboori n. sp. (Acari: Microtrombidiidae: Valgothrombiinae) is described and illustrated based on larvae collected from soil, i.e. off their host from Riseh village, Shahre Babak city, Kerman province, Iran. This is the first record of Valgothrombium for Iranian mite fauna and $15^{\text {th }}$ species of the genus based on the larva. In Asia, the genus Valgothrombium is reported from China, Bhutan, Yemen from larval form, and Japan and Malaysia from post-larval forms.
\end{abstract}

Keywords: Larva, new record, Prostigmata, taxonomy, Trombidiformes.

Zoobank: http://zoobank.org/D1CB1E99-1715-4A42-873C-3F3EFC4E42ED

\section{INTRODUCTION}

One of the largest family in group of Parasitengona is Microtrombidiidae with about 450 species in 126 genera, all of which are parasites of arthropods as larvae (Mąkol and Wohltmann, 2012; Masoumi et al., 2016; Mąkol et al., 2017). Valgothrombiinae is a subfamily of Microtrombidiidae that comprises 12 genera. Valgothrombium comprises 31 species, of them, 17 species are known exclusively from post-larval forms, 11 from larvae, whereas only three from both larval and post-larval forms (Mąkol and Wohltmann, 2012; Buğa and Sevsay 2020). It is reported from China, Bhutan, Yemen in Asia from larval form, and Japan and Malaysia from post-larval forms. It is the first report of Valgothrombium from Iran.

In this paper, we describe a new species, Valgothrombium takhtii Saberi-Riseh \& Saboori n. sp. based on larva and collected from soil in Riseh village, Shahre Babak city, Kerman province, Iran.

\section{MATERIALS AND METHODS}

Three specimens were collected in Riseh Village $\left(30^{\circ} 19^{\prime}\right.$ $00^{\prime \prime} \mathrm{N}, 55^{\circ} 24^{\prime} 33^{\prime \prime}$ E, $2498 \mathrm{~m}$ a.s.l), Shahre Babak city, Kerman province, southern Iran. They were extracted from soil using a Berlese funnel and separated under a stereomicroscope. The specimens were cleared in Nesbitt's fluid and mounted on glass microscope slides using Faure's medium (Walter and Krantz, 2009). Figures were drawn and measurements (given in micrometers) were made using a BX 51 phase contrast Olympus microscope equipped with a drawing tube. The terminology and abbreviations are adapted from Makol and Łaydanowicz (2010).

\section{RESULTS}

Microtrombidiinae Thor, 1935

Subfamily Valgothrombiinae Gabryś, 1999

Genus Valgothrombium Willmann, 1940

Type species: Ottonia valga George, 1909

Valgothrombium takhtii Saberi-Riseh \& Saboori n. sp.

Diagnosis

Larva with following features: Dorsum of idiosoma with two shields; median ridge present on posterior part of the scutum. Scutum punctate and rectangle, and scutellum punctate; palp femur and palp genu without setae; $\mathrm{fD}=$ $4(+2)-6-6-6-4=26(+2) ; \mathrm{fV}=2-2 \mathrm{u}=4 ; \mathrm{fnGe}=4-2-2 ; \mathrm{IP}=$ 490-503.

\section{Description $(\mathrm{n}=3)$}

Colour in life red. Idiosoma oval, Metric data given in Table 1.

Dorsal idiosoma (Fig. 1) with a scutum, a scutellum; hysterosoma with 28 barbed setae, each placed on a large sclerite except $c_{1}$ on scutellum and terminal setae. Setal sclerites (largest bearing setae $c_{2}$ and $d_{1}$ ) sparsely punctated. Dorsal setae arranged in five rows $\left(c_{1-3}, d_{1-3}, e_{1-3}, f_{1-}\right.$ ${ }_{3}, h_{1-2}$ ) (Fig. 1). Setae $f_{3}$ and $h_{1}-h_{2}$ are seen on the ventral side of idiosoma. Scutum rectangular in outline and distinctly longer than wide, with slight antero-medial protrusion and rounded anterolateral angles. Scutum with a posteriorly protruding ridge along its median axis (Fig. 1); scutum with bearing 3 pairs of normal setae (AM, AL and PL) and 1 pair of trichobothria (S). AM and AL with setules and PL slightly thicker than AM and barbed. S filiform 
and smooth. Paired eyes at the level of posterior part of scutum, each pair composed of anterior and posterior lens (anterior 6-7 in diameter, posterior: 4-5), situated on a smooth oval sclerite. Scutellum wider than long, bearing one pair of barbed $c_{1}$ setae. Antero- and posteromedian parts of scutellum with distinct concavity, other parts of scutellum convex.

Ventral idiosoma (Fig. 2) with smooth cuticle. Claparéde's organs laterally between coxae I and II. Coxa I with $1 a$ and $1 b$ setae with one setula. Coxa II with antero-lateral seta $2 b$ with one setula. Coxa III with single antero-lateral seta $3 b$, with one setula. $f C x$ formula $=$ BB-B-B. Idiosoma without intercoxal setae $(3 a)$ between coxae III, 2 pairs of ventral setae with distinct barbs and a uropore. Anal opening without sclerite. $f \mathrm{~V}$ formula $=2 \mathrm{u}-2$. NDV $=28(+$ 2) $+4=30(+2)$.

Gnathosoma (Fig. 3) with hypostomal setae (bs) short, small spine-like, a pair of nude adoral setae (or). Cheliceral blade slightly curved, with small denticle in distal part of its inner edge. Palpal femur and genu without setae. Palp tibia with one long smooth seta and two shorter, thorn-like setae. Palpal tibial claw bifid. Palpal tarsus with one solenidion, one eupathidium, one very long nude setae and 3 very short nude setae. fPp $=0-0-0-\mathrm{NNN}_{2}-$ NNNN $\omega \zeta$.

Leg segmentation formula: 6-6-6. Leg setal formula (Figs 4-12): Leg I: $\operatorname{Tr}(1 n)-F e(6 n)-G e(4 n, 2 \sigma, 1 \kappa)-\operatorname{Ti}(6 n, 2 \varphi$, $1 \kappa)$ - Ta $(17 n, 2 \zeta, 1 \omega, 1 \varepsilon)$. Leg II: Tr (1n) - Fe (5n) - Ge (2n, $1 \sigma)$ - Ti $(5 n, 2 \varphi)$ - Ta $(14-15 n, 1 \zeta, 1 \omega, 1 \varepsilon)$. Leg III: Tr (1n) - Fe (4n) - Ge $(2 n, 1 \sigma)$ - Ti (5n) - Ta (13n). Fe I with two and Fe II \& III with one nude setae. Ta I \& II with two falciform claws; Ta III with two falciform claws and a slender claw-like empodium. Each claw has a subterminal spur on each side (Figs 6, 9, 12). Measurements given in Table 1.

\section{Type material}

The holotype (ARS-20200528-1a) and two paratypes (ARS-20200528-1b, 1c) were collected by Nasir SaberiRiseh, 22 June 2018. Larvae were collected from soil under walnut tree, Riseh village $\left(30^{\circ} 19^{\prime} 00^{\prime \prime} \mathrm{N}, 55^{\circ} 24^{\prime} 33^{\prime \prime}\right.$ E, 2498 m a.s.l), Shahre Babak city, Kerman Province, southern Iran. The holotype (ARS-20200611-1a) and one paratype (ARS-20200611-1b) are deposited in the Acarological Collection, Jalal Afshar Zoological Museum (JAZM), Faculty of Agriculture, University of Tehran, Karaj, Iran. Other paratype (ARS-20200611-1c) are deposited in the Acarological Collection, Acarological Society of Iran, Department of Plant Protection, Faculty of Agriculture, University of Tehran, Karaj, Iran

\section{Etymology}

This species is named in memory of Gholamreza Takhti (August 27, 1930 - January 7, 1968) was an Iranian Olympic Gold-Medalist wrestler. Popularly nicknamed
Jahān Pahlevān ("The World Champion") because of his chivalrous behavior and sportsmanship, he was the most popular athlete of Iran in the 20th century, although dozens of Iranian athletes have won more international medals than he did. Takhti is still a hero to many Iranians. He is listed in the FILA wrestling hall of fame.

\section{Remarks}

Valgothrombium takhtii Saberi-Riseh \& Saboori n. sp. differs from other species of the genus in the shape of the scutum and scutellum, in V. takhtii Saberi-Riseh \& Saboori n. sp. scutum is punctate and rectangle, and scutellum entirely punctate, whereas in other species of Valgothrombium scutum is pentagonal, oval or semicircular, except for $V$. melindae Haitlinger, 2008, V. valgum George, 1909, V. tarnavense Feider, 1950 and V. andreae Saboori, Ueckermann \& van Harten, 2007, where the general shape of the scutum and scutellum is similar to $V$. takhtii. Valgothrombium takhtii n. sp. differs from $V$. melindae in shorter AL (27-28 vs. 35 in V. melindae), PL (40-41 vs. 62), IP (490-503 vs. 532) and longer L/W (1.58-1.64 vs. 1.39), median ridge on scutum originated between sensillary and PL setal bases (median ridge on scutum originated from bases of sensillary setae in $V$. melindae), setae $c_{1}$ placed in the mid-line of scutellum (vs. placed in the posterior half of scutellum); from $V$. valgum by fD (28 vs. 26 in V. valgum), WS (47-50 vs. 55), HS (4849 vs. 55), IP (490-503 vs. 535-561), shorter S (27-29 vs. 32 ), median ridge on scutum originated between sensillary and PL setal bases (vs. median ridge on scutum originated between base of sensillary setae), scutum longer than scutellum (vs. scutum and scutellum with the same length), anterior border of scutum convex (vs. anterior border of scutum straight); from $V$. tarnavense, two claws and an empodium are present on all tarsi and scuttelum seems larger than scuttum, number of setae on Fe II ( 5 vs. 4), on Fe III (4 vs. 3), on Ge I-III (4-2-2 vs. 3-3-3) and longer HS (48-49 vs. 81), from $V$. andreae with median ridge on scutum originated between sensillary and PL setal bases (median ridge on scutum originated prior to the base of sensillary setae in V. andreae), without mushroom-like projections on dorsal idiosoma (vs. with mushroom-like projections on dorsal idiosoma), posterolateral part of coxae II normal (vs. posterolateral part of coxae II with protrusion), coxal setae with unequal branches (vs. with equal branches), IP (490-503 vs. 419-460), AL (2728 vs. $17-22$ ) and PL (40-41 vs. $30-35)$.

\section{Funding}

The research on which this paper was based was supported by a grant (No. 7110018/6/25) from the University of Tehran which is greatly appreciated.

\section{Conflict of interest}

No potential conflict of interest was reported by the authors. 


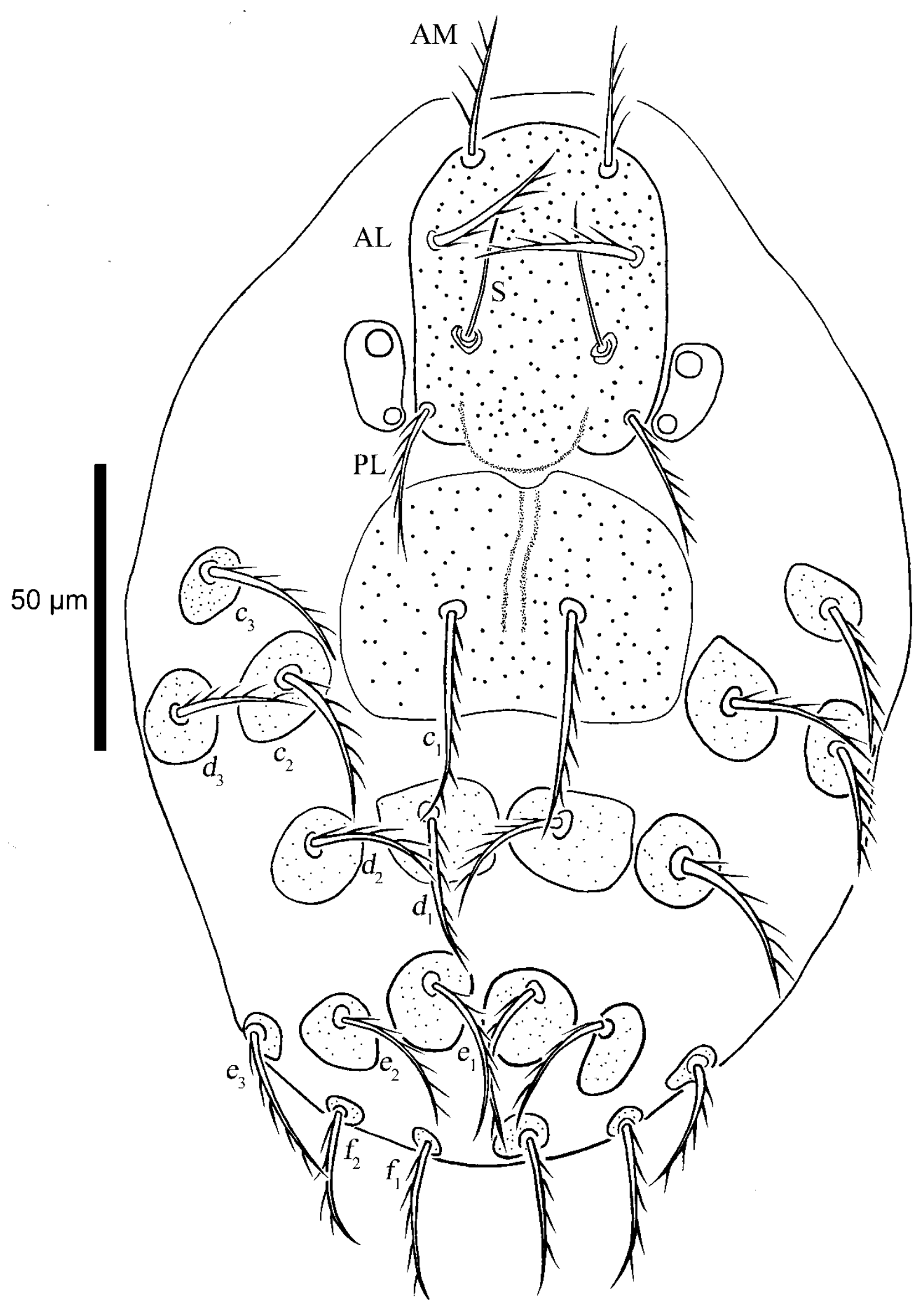

Figure 1. Valgothrombium takhtii Saberi-Riseh \& Saboori n. sp. (larva) - Dorsal view of idiosoma (AM = Anteromedian seta, $\mathrm{AL}=$ Anterolateral seta, $\mathrm{PL}=$ Posterolateral seta, $\mathrm{S}=$ Sensillary seta). 


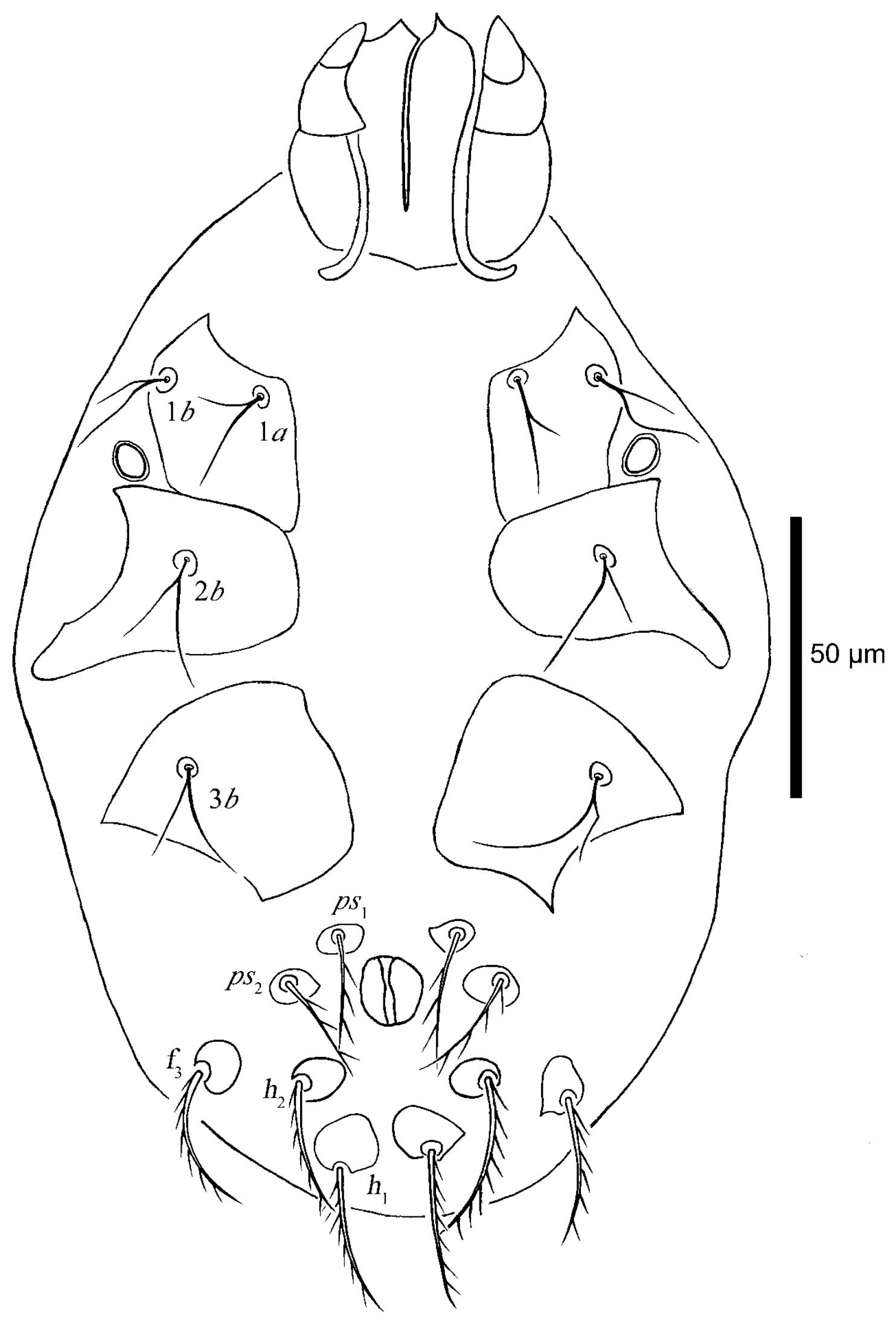

Figure 2. Valgothrombium takhtii Saberi-Riseh \& Saboori n. sp. (larva) - Ventral view of idiosoma. 


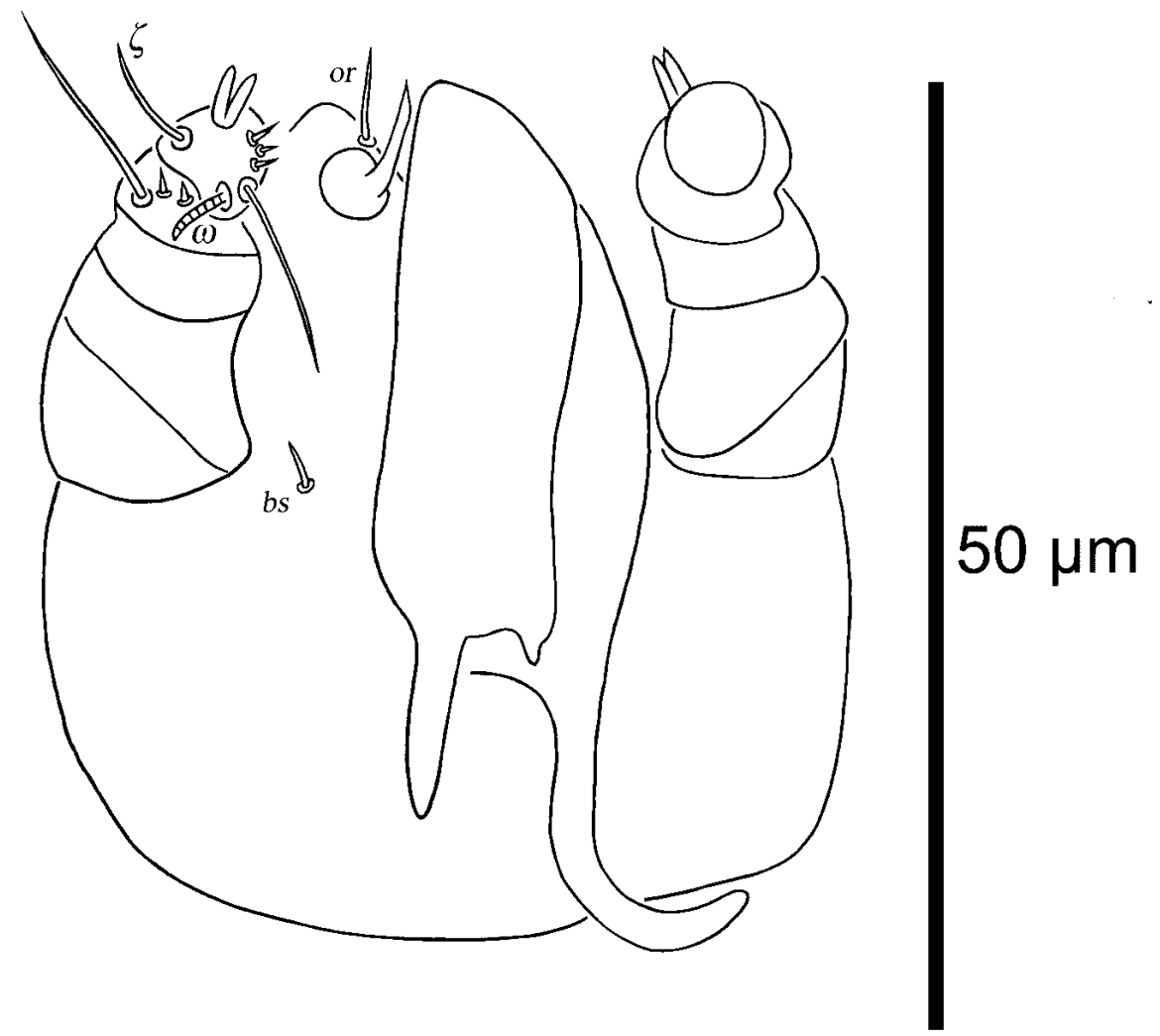

Figure 3. Valgothrombium takhtii Saberi-Riseh \& Saboori n. sp. (larva) - Dorsal view (right) and ventral view (left) of gnathosoma.

Table 1. Metric data for larvae of Valgothrombium takhtii Sabori-Riseh \& Saboori n. sp. (1a, holotype; 1b-1c, paratypes).

\begin{tabular}{cccccccc}
\hline Character & $1 \mathrm{a}$ & $1 \mathrm{~b}$ & $1 \mathrm{c}$ & Character & $1 \mathrm{a}$ & $1 \mathrm{~b}$ & $1 \mathrm{c}$ \\
\hline LB & 213 & 186 & 200 & Ta I (L) & 35 & 34 & 34 \\
WB & 134 & 113 & 125 & Ta I (W) & 18 & 20 & 19 \\
LB/WB & 1.58 & 1.64 & 1.60 & Ti I & 26 & 24 & 26 \\
AW & 36 & 35 & 35 & Ge I & 17 & 16 & 17 \\
PW & 38 & 40 & 39 & Fe I & 37 & 37 & 36 \\
AA & 24 & 18 & 20 & Tr I & 24 & 23 & 24 \\
SB & 24 & 26 & 25 & Cx I & 40 & 38 & 40 \\
ASB & 38 & 34 & 36 & Leg I & 179 & 172 & 177 \\
PSB & 19 & 24 & 21 & Ta II (L) & 28 & 27 & 28 \\
LS & 57 & 58 & 57 & Ta II (W) & 16 & 17 & 16 \\
WS & 47 & 50 & 48 & Ti II & 22 & 20 & 21 \\
AP & 29 & 30 & 30 & Ge II & 15 & 15 & 16 \\
MA & 16 & 15 & 16 & Fe II & 35 & 32 & 33 \\
AL & 28 & 27 & 28 & Tr II & 24 & 21 & 22 \\
PL & 41 & 41 & 40 & Cx II & 37 & 40 & 38 \\
AM & 30 & 31 & 30 & Leg II & 161 & 155 & 158 \\
S & 27 & 29 & 28 & Ta III (L) & 32 & 30 & 32 \\
SL & 43 & 47 & 44 & Ta III (W) & 14 & 15 & 15 \\
SS & 22 & 21 & 22 & Ti III & 20 & 21 & 20 \\
HS & 48 & 49 & 49 & Ge III & 15 & 13 & 15 \\
LSS & 64 & 66 & 65 & Fe III & 31 & 34 & 34 \\
PDS & 31 & 29 & 30 & Tr III & 25 & 25 & 24 \\
DS & $27-32$ & $27-35$ & $27-33$ & Cx III & 41 & 40 & 39 \\
or & 6 & - & 7 & Leg III & 163 & 163 & 164 \\
$b s$ & 4 & 4 & 5 & IP & 503 & 490 & 499 \\
\hline
\end{tabular}



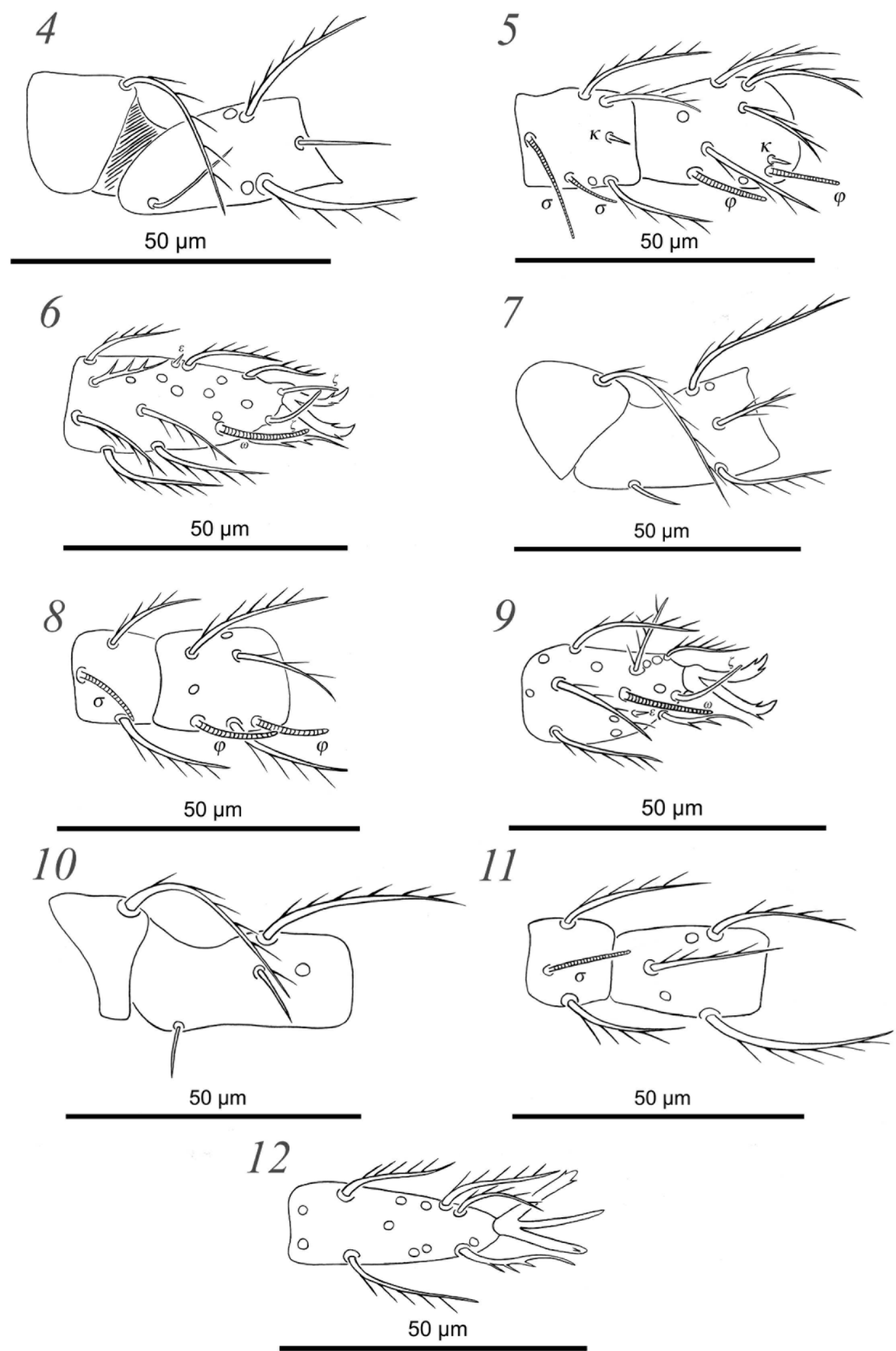

$50 \mu \mathrm{m}$

Figures 4-12. Valgothrombium takhtii Saberi-Riseh \& Saboori n. sp. (larva) - 4. Trochanter and femur I, 5. Genu and tibia I, 6. Tarsus I, 7. Trochanter and femur II, 8. Genu and tibia II, 9. Tarsus II, 10. Trochanter and femur III, 11. Genu and tibia III, 12. Tarsus III. 


\section{REFERENCES}

Buğa, E. and Sevsay, S. 2020. A contribution to the knowledge of the genus Valgothrombium Willmann, 1940 (Acari: Microtrombidiidae) from Turkey. Systematic and Applied Acarology, 25 (1): 1-16.

doi: $10.11158 /$ saa.25.1.1

Mąkol, J., Felska, M. and Król, Z. 2017. New genus and species of microtrombidiid mite (Actinotrichida: Trombidioidea, Microtrombidiidae) parasitizing spiders (Araneae: Araneidae) in Costa Rica. Acarologia, 57 (3): 517-527.

doi: 10.24349/acarologia/20174174

Makol, J. and Łaydanowicz, J. 2010. A new species of Valgothrombium Willmann, 1940, with additional taxonomic data for Valgothrombiinae genera known as larvae (Acari: Prostigmata: Microtrombidiidae). Zootaxa, 2647: 16-34.

doi: 10.11646/zootaxa.2647.1.2

Mąkol, J. and Wohltmann, A. 2012. An annotated checklist of terrestrial Parasitengona (Actinotrichida: Prostig- mata) of the world, excluding Trombiculidae and Walchiidae. Annals Zoologici, 62 (3): 359-562. doi: $10.3161 / 000345412 \times 656671$

Masoumi, H., Saboori, A. and Seiedy, M. 2016. First nonEuropean species of the genus Montenegtrombium (Acari: Microtrombidiidae) ectoparasitic on Acrididae (Orthoptera) from Iran. Systematic and Applied Acarology, 21 (3): 288-294.

doi: 10.11158/saa.21.3.4

Saboori, A., Ueckermann, E.A. and van Harten, A. 2007. A new genus and species of Microtrombidiidae (Acari) from Yemen. International Journal of Acarology, 33 (2): 163-166. doi: $10.1080 / 01647950708684518$

Walter, D.E. and Krantz, G.W. 2009. Collecting, rearing, and preparing specimens. In: A manual of Acarology. 3rd ed. Krantz GW and Walter D.E. (Eds). Texas Tech University Press, Lubbock, Texas, USA, 83-96.

Edited by: Salih Doğan

Reviewed by: Two anonymous referees

Citation: Saberi-Riseh, N., Saboori, A., Asadi, M., Zahadi Golpayegani, A. and Nozari, J. 2020. The first record of Valgothrombium (Acari: Microtrombidiidae) from Iran with description of a new species. Acarological Studies, 2 (2): 119-125. 